\title{
Composite GPS Patch Antenna for the AR Bandwidth Enhancement
}

\author{
Minkil Park, Wonhee Lee, and Taeho Son \\ Department of Information and Communication Engineering, Soonchunhyang University, Asan, Chungnam 31538, Republic of Korea
}

Correspondence should be addressed to Taeho Son; thson@sch.ac.kr

Received 21 October 2015; Accepted 5 January 2016

Academic Editor: Xiulong Bao

Copyright (C) 2016 Minkil Park et al. This is an open access article distributed under the Creative Commons Attribution License, which permits unrestricted use, distribution, and reproduction in any medium, provided the original work is properly cited.

A composite Global Positioning System (GPS) patch antenna with a quadrature 3 dB hybrid coupler was designed and implemented for working RHCP and had a broadband axial ratio (AR) bandwidth. We designed two patches as a FR-4 patch and $1.5 \mathrm{~mm}$ thickness thin ceramic patch with a quadrature $3 \mathrm{~dB}$ hybrid coupler. A CP radiation pattern was achieved, and the AR bandwidth improved by incorporating a quadrature $3 \mathrm{~dB}$ hybrid coupler feed structure in a micro-strip patch antenna. SMD by chip elements was applied to the quadrature $3 \mathrm{~dB}$ hybrid coupler. For the composite FR- 4 and ceramic patch antennas, the VSWR measurement showed a $2: 1$ ratio over the entire design band, and the $3 \mathrm{~dB}$ AR bandwidth was 295 and $580 \mathrm{MHz}$ for the FR- 4 patch and ceramic patch antennas, respectively. The antenna gains for the composite FR-4 and ceramic patch antennas were measured as $1.36-2.75$ and $1.47-2.71 \mathrm{dBi}$ with $15.11-25.3 \%$ and $19.25-28.45 \%$ efficiency, respectively.

\section{Introduction}

Global Positioning System (GPS) has fully been deploying and has advantage of higher precision and low cost compared to other navigation systems. An antenna for GPS requires higher performance, such as broadband, RHCP, and $3 \mathrm{~dB}$ axial ratio (AR), CP radiation, high gain, and CP beam-width. Reducing multipath especially is an important factor of GPS antenna [1,2]; the good axial ratio performance can reduce multipath of GPS signal. Studies of the improvement for axial ratio related multipath mitigation have been investigated [3-5]. Various techniques such as micro-strip patch [611], crossed dipole [12], and near-field resonance parasitic have been studied [13, 14]. Most of these studied have broadband impedance bandwidths. However, these studied do not have broadband $3 \mathrm{~dB}$ AR bandwidths to satisfy the requirement of GPS and that does not treat enhancement $3 \mathrm{~dB}$ bandwidth of the AR. Actually, an antenna with GPS receiver performance depends on the bandwidth of the AR, because the signal contact rate is proportional to bandwidth of the AR. Therefore the bandwidth of AR is the most important factor. In this paper, broadband ceramic patch antenna and broadband $\mathrm{CP}$ bandwidth were achieved in the quadrature $3 \mathrm{~dB}$ hybrid coupler, which were fabricated SMD type chip elements $L, C$.
This paper introduces composite FR-4 patch antenna and composite ceramic patch antenna with a quadrature $3 \mathrm{~dB}$ hybrid coupler feed structure. The main purpose of this study is for helping GPS patch antenna design which is currently in difficulty of thin thickness caused by the narrow bandwidth. A quadrature $3 \mathrm{~dB}$ hybrid coupler has characteristic of broadband impedance bandwidths and that input power is split equally between through port and coupled port with 90-degree phase difference. CP radiation was achieved, and the AR was improved by the characteristic of a quadrature $3 \mathrm{~dB}$ hybrid coupler and compared to that of composite FR4 micro-strip patch antenna and composite ceramic patch antenna. The paper is organized into the following sections: Section 2 describes the principle of the micro-strip patch antenna design, Section 3 describes the principle of the quadrature $3 \mathrm{~dB}$ hybrid coupler design, Section 4 compared composite FR-4 patch antenna and micro-strip antenna, and Section 5 compared composite FR- 4 patch antenna and composite ceramic patch antenna, while the paper is concluded in Section 6.

\section{Design of FR-4 Micro-Strip Patch Antenna}

Figure 1 shows the geometry of the micro-strip patch antenna without a quadrature $3 \mathrm{~dB}$ hybrid coupler. The micro-strip 


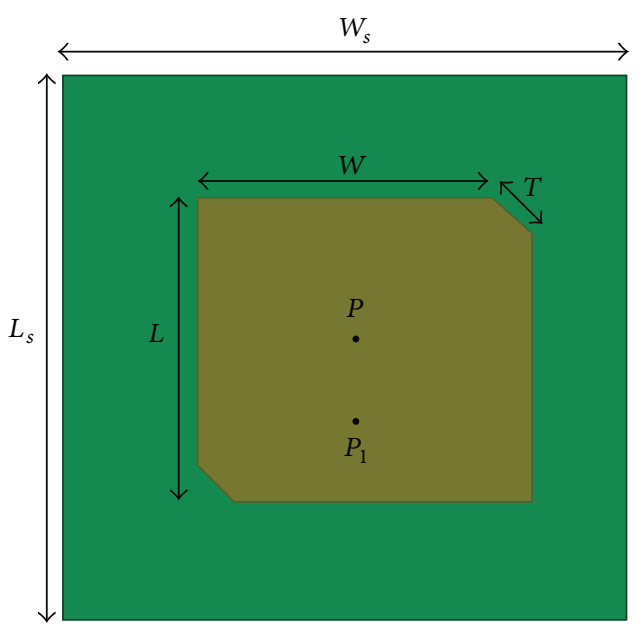

FIGURE 1: Geometry of the FR-4 micro-strip patch antenna.

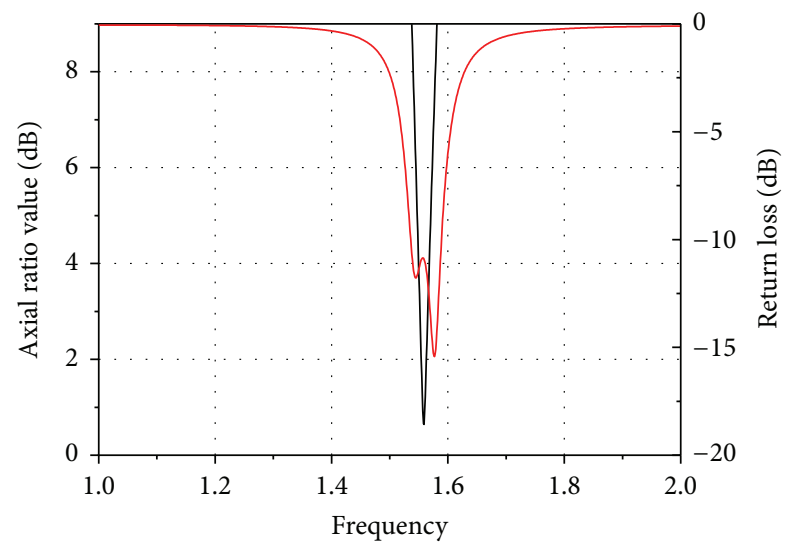

- Axial ratio

— Return loss

FIGURE 2: Simulated return loss and axial ratio.

patch antenna was designed as truncated type for CP radiation. The micro-strip patch antenna is working at $1.575 \mathrm{GHz}$ and with RHCP radiation. The antenna was printed on a rectangular FR-4 Epoxy with relative permittivity of 4.7, a loss tangent of 0.019 , with a face of $75 \mathrm{~mm} \times 80 \mathrm{~mm}$, and a thickness of $1.5 \mathrm{~mm}$. The antenna was fed to a coaxial cable. The inner conductor of the coaxial cable was through the substrate and connected to the micro-strip patch. The outer conductor of the coaxial cable was connected to the bottom ground of the substrate. The antenna was optimized via HFSS by three-dimensional EM simulation software of ANSYS. CP center frequency at $1.575 \mathrm{GHz}$ was the defined frequency of minimum AR. The optimized antenna design parameters were as follows: $W=44.3 \mathrm{~mm}, L=44.3 \mathrm{~mm}$, $W_{s}=75 \mathrm{~mm}, L_{s}=80 \mathrm{~mm}, T=7 \mathrm{~mm}$, and $P=11 \mathrm{~mm}$ from center of micro-strip patch. Figure 2 shows the simulated return loss and AR values of micro-strip patch antenna. The bandwidth of patch antenna ranges from $1.53 \mathrm{GHz}$ to $1.6 \mathrm{GHz}$ at $-10 \mathrm{~dB}$ and $\mathrm{CP}$ center frequency was $1.575 \mathrm{GHz}$ that the $3 \mathrm{~dB}$ bandwidth was from $1.55 \mathrm{GHz}$ to $1.58 \mathrm{GHz}$, and gain was $1.44 \mathrm{dBi}$. These results were obtained for the FR- 4 micro-strip antenna without a quadrature $3 \mathrm{~dB}$ hybrid coupler.

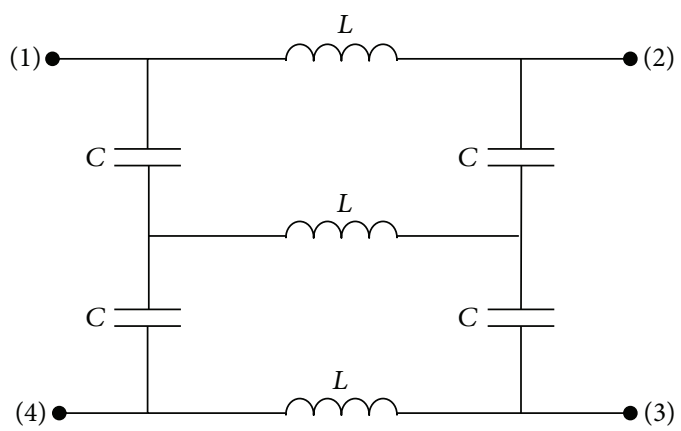

Ports:
(1) Input
(3) Coupled
(2) Through
(4) Isolated

Figure 3: Basic lumped element hybrid coupler circuit [8].

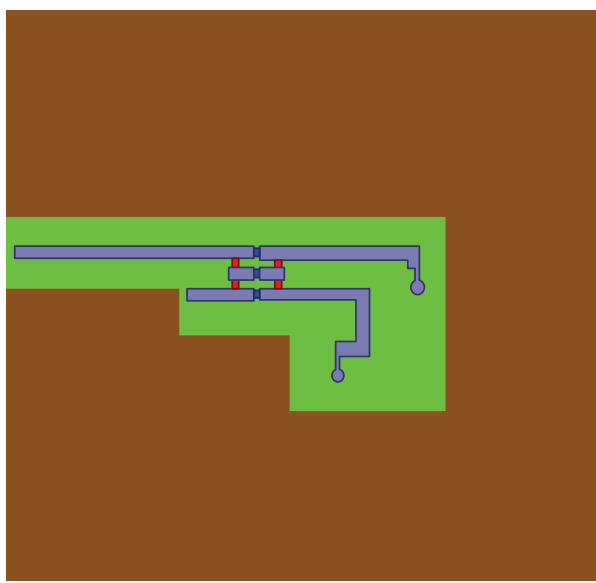

FIGURE 4: Layout of the quadrature $3 \mathrm{~dB}$ hybrid coupler using HFSS.

\section{Design of a Quadrature 3 dB Hybrid Coupler}

A quadrature $3 \mathrm{~dB}$ hybrid coupler is widely used in microwave circuit. The hybrid coupler splits the input power equally between through and coupled ports with 90-degree phase difference and with wide impedance bandwidth [15, 16], where CP radiation of antenna is working when with equal power and 90-degree difference at two feed points. Therefore, the antenna could achieve wideband CP radiation used feed system with the quadrature $3 \mathrm{~dB}$ hybrid coupler.

Figure 3 shows a basic lumped element hybrid coupler circuit: Port 1, input; Port 2, through; Port 3, coupled; and Port 4, isolation. $L, C$ value computed from frequency and characteristic impedance as shown in (1) can be obtained:

$$
\begin{aligned}
L & =\frac{Z_{0}}{2 \pi f} \mathrm{nH}, \\
C & =\frac{1}{\left(Z_{0} 2 \pi f\right)} \mathrm{pF} .
\end{aligned}
$$

Figure 4 shows layout of the quadrature $3 \mathrm{~dB}$ hybrid coupler using HFSS. The optimized hybrid coupler design $L, C$ values 


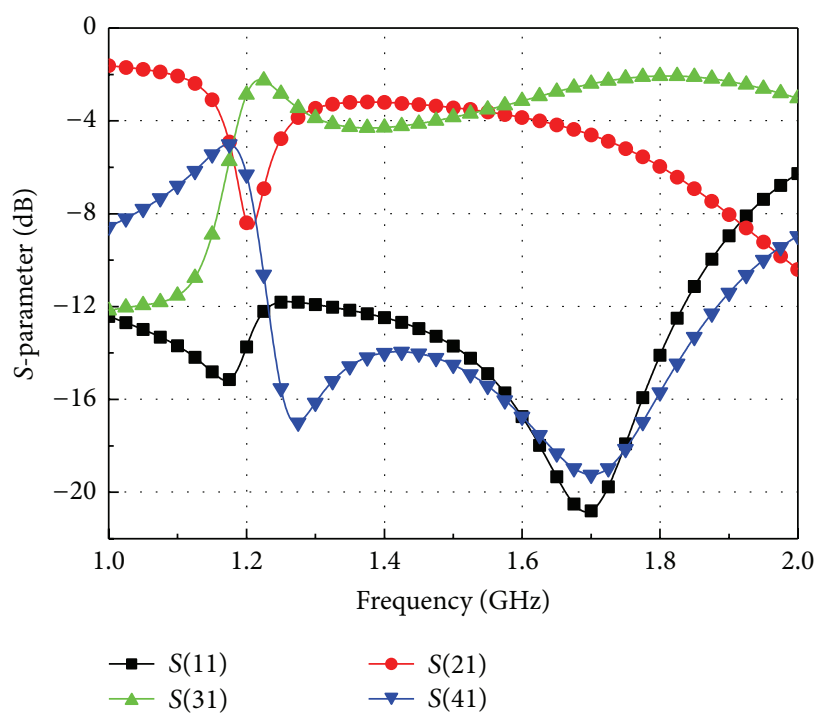

(a)

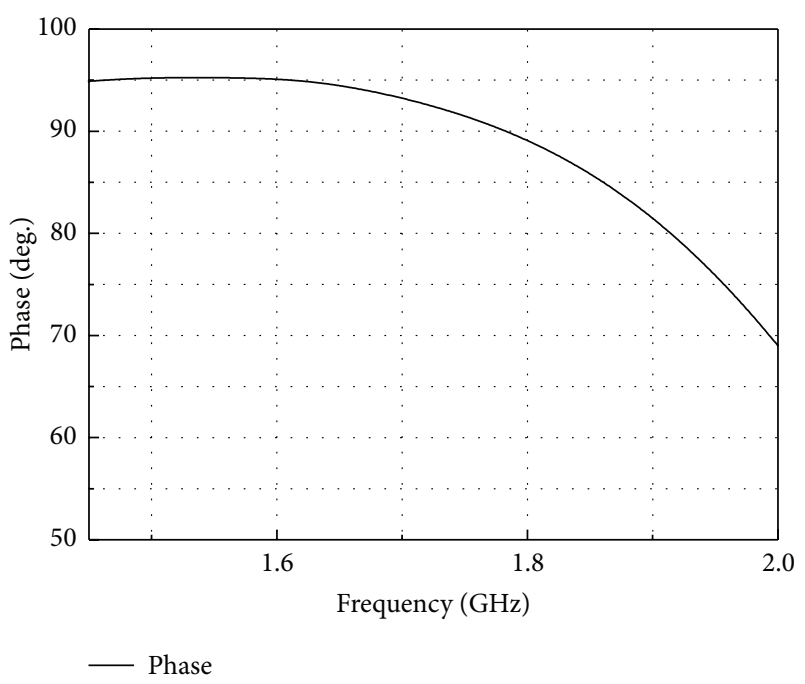

(b)

FIgURE 5: (a) Measured S-parameter and (b) between-two-ports phase difference.

were as follows: $C=1.8 \mathrm{pF}, L=4.8 \mathrm{nH}$. The quadrature $3 \mathrm{~dB}$ hybrid coupler was printed on rectangular FR-4 Epoxy with relative permittivity of 4.7 , a loss tangent of 0.019 , with face of $75 \mathrm{~mm} \times 80 \mathrm{~mm}$, and a thickness of $1.2 \mathrm{~mm}$. Figure 5(a) shows measured $S$-parameters result. The through and coupled ports had $3 \pm 1 \mathrm{~dB}$, and impedance bandwidths are in the range of 1.28 to $1.68 \mathrm{GHz}$ below $-14 \mathrm{~dB}$. The isolation was higher than $-19 \mathrm{~dB}$. Figure $5(\mathrm{~b})$ shows phase difference between through port and coupled port. The phase difference between through port and coupled port was $90 \pm 5$ degrees for band in $1.45 \mathrm{GHz}$ to $1.9 \mathrm{GHz}$ that is available bandwidths for $\mathrm{CP}$ radiation of micro-strip patch antenna.

\section{Composite FR-4 Patch Antenna with a Quadrature 3 dB Hybrid Coupler}

A CP radiation pattern was achieved and AR bandwidths were improved by incorporating a quadrature $3 \mathrm{~dB}$ hybrid coupler feed structure in micro-strip patch antenna. Geometry of the composite FR-4 patch antenna was given in Figure 6. The optimized antenna design parameters were as follows: $W=44.3 \mathrm{~mm}, L=44.3 \mathrm{~mm}, W_{s}=75 \mathrm{~mm}, L_{s}=$ $80 \mathrm{~mm}, P$ is center of patch, $P_{1}=11 \mathrm{~mm}$ from $P$, and $P_{2}=11$ from $P$. Figure 7 (a) shows measured return loss $\left(S_{11}\right)$ for the proposed composite FR-4 patch antenna. The resonance frequency was $1.575 \mathrm{GHz}$. The measured bandwidth for $-10 \mathrm{~dB}$ return loss was from $1.27 \mathrm{GHz}$ to $1.69 \mathrm{GHz}$. Compared to micro-strip patch antenna, the bandwidth of the proposed composite FR-4 patch antenna was improved compared to micro-strip patch antenna. Figure 7(b) shows measured AR for the proposed composite FR- 4 patch antenna. The measured $3 \mathrm{~dB}$ AR bandwidth was from $1.325 \mathrm{GHz}$ to $1.62 \mathrm{GHz}$. The AR bandwidth of the proposed composite FR-4 patch

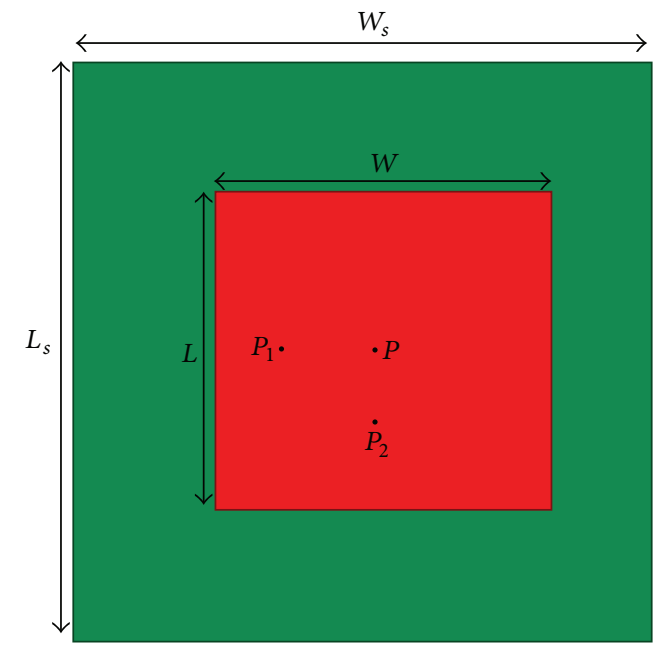

FIGURE 6: Geometry of composite FR-4 patch antenna.

antenna also was improved compared to micro-strip patch antenna. As shown in Figure 7, the proposed composite FR-4 patch antenna was the obtained result that could cover for the whole GPS band.

\section{Composite Ceramic Patch Antenna with a Quadrature 3 dB Hybrid Coupler}

A small size antenna was achieved using ceramic substructure, and also a CP radiation pattern was achieved and AR bandwidths were improved by incorporating a quadrature $3 \mathrm{~dB}$ hybrid coupler feed structure in ceramic patch antenna. And next, compare to composite FR-4 patch 


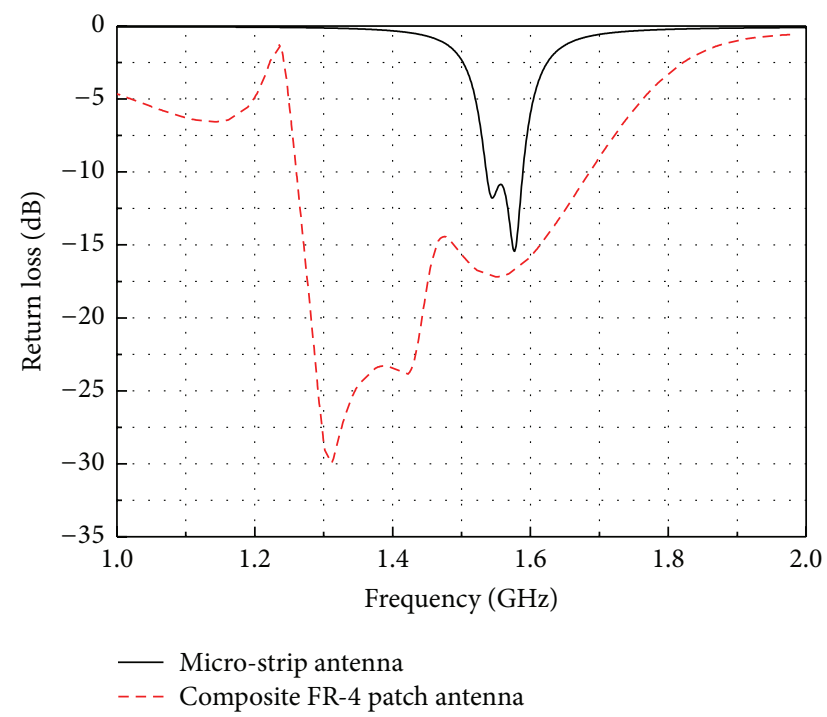

(a)

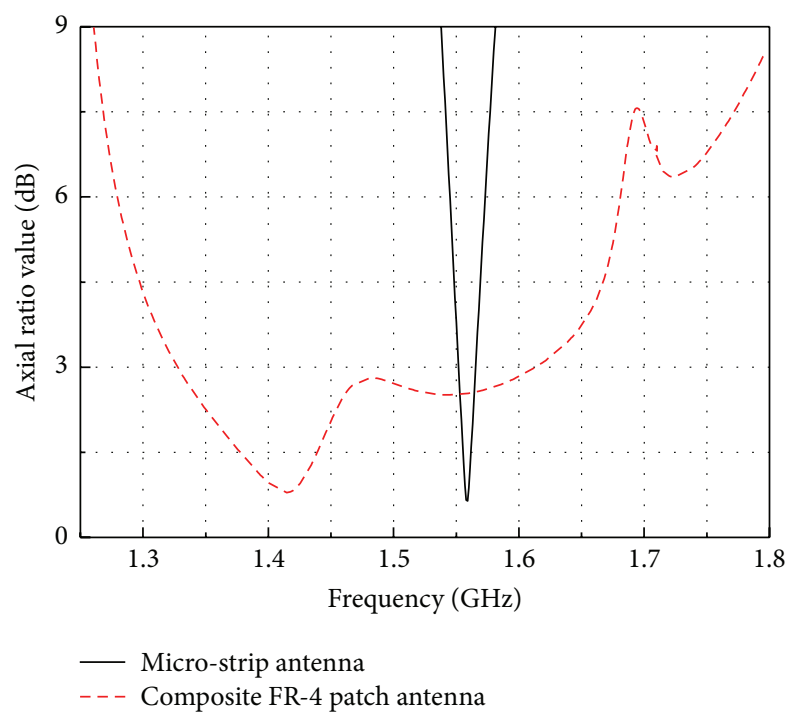

(b)

FIGURE 7: Comparison of the composite FR-4 antenna and micro-strip antenna. (a) Measured impedance bandwidth, (b) AR bandwidth.

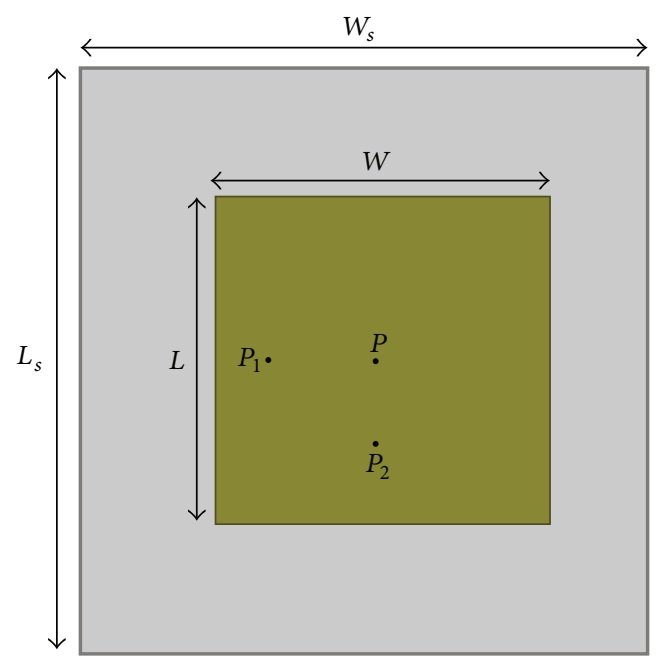

FIGURE 8: Geometry of composite ceramic patch antenna.

antenna. Ceramic had high relative permittivity made to shorten wavelength, to reduce antenna size, and to use high relative permittivity.

Figure 8 shows the geometry of the composite ceramic patch antenna on ceramic. The optimized antenna design parameters were as follows: $W=19 \mathrm{~mm}, L=19 \mathrm{~mm}$, $W_{s 1}=25 \mathrm{~mm}, L_{s 1}=25 \mathrm{~mm}, P^{\prime}$ is center of patch, port $1=3 \mathrm{~mm}$ from $P^{\prime}$, and port $2=11$ from $P^{\prime}$. The antenna was designed on ceramic substrate with a face of $25 \mathrm{~mm} \times 25 \mathrm{~mm}$, a relative permittivity of 21 , a loss tangent of 0.00028 , and a thickness of $1.5 \mathrm{~mm}$. The antenna is fed $50 \Omega$ coaxial port. The antenna was optimized via HFSS by 3-dimension EM simulation software of ANSYS. Figure 9(a) shows measured return loss $\left(S_{11}\right)$ for the proposed composite ceramic patch antenna. The resonance frequency was $1.575 \mathrm{GHz}$. The measured bandwidth for $-10 \mathrm{~dB}$ return loss was from $1.412 \mathrm{GHz}$ to $1.851 \mathrm{GHz}$. Compared to composite FR-4 patch antenna, the bandwidth of the proposed composite ceramic patch antenna was wider than composite FR-4 patch antenna. Figure 9(b) shows measured AR for the proposed composite ceramic patch antenna. The measured $3 \mathrm{~dB}$ AR bandwidth was from $1.2 \mathrm{GHz}$ to $1.78 \mathrm{GHz}$. The AR bandwidth of the proposed composite ceramic patch antenna also was wider than composite FR-4 patch antenna. As shown in Figure 9, the proposed antenna was the obtained result that could cover for the whole GPS band.

Table 1 shows measured composite FR-4 patch antenna and composite ceramic patch antennas $\mathrm{CP}$ gain and $\mathrm{AR}$ using the quadrature $3 \mathrm{~dB}$ hybrid coupler. As shown in Table 1 the proposed CP of composite FR- 4 antenna was worked RHCP, and measured antenna peak gain has good performance as $1.36 \mathrm{dBi}$ to $2.75 \mathrm{dBi}$. Also AR value was $3 \mathrm{~dB}$ at target frequencies, and also composite ceramic patch antenna was worked RHCP, measured antenna peak gain had good performance as $1.47 \mathrm{dBi}$ to $2.71 \mathrm{dBi}$, and $A R$ value was $3 \mathrm{~dB}$ at target frequencies.

\section{Conclusion}

Broadband RHCP patch antenna using a quadrature $3 \mathrm{~dB}$ hybrid coupler for GPS has been proposed. The antenna has been implemented and tested. The proposed composite FR4 antenna bandwidth $(-10 \mathrm{~dB})$ was broadband as $1.56 \mathrm{GHz}$ to $1.69 \mathrm{GHz}$ and broadband to cover AR bandwidth of $1.56 \mathrm{GHz}$ to $1.62 \mathrm{GHz}$ as $3 \mathrm{~dB}$ AR value. And gain had good performance as $1.46 \mathrm{dBi}$ to $2.75 \mathrm{dBi}$.

Also, the proposed ceramic antenna bandwidth $(-10 \mathrm{~dB})$ was broadband as $1.412 \mathrm{GHz}$ to $1.851 \mathrm{GHz}$ and broadband 


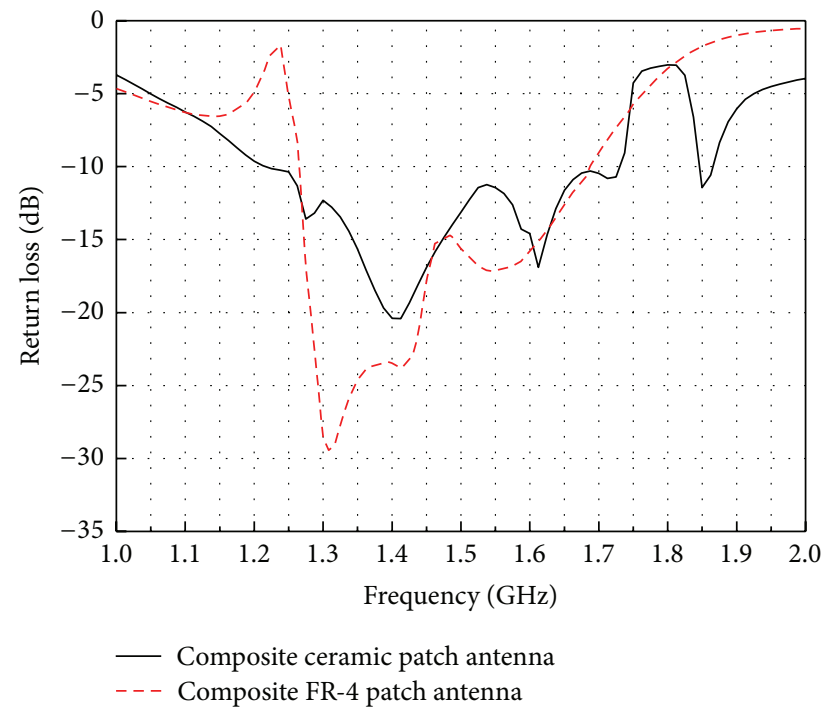

(a)

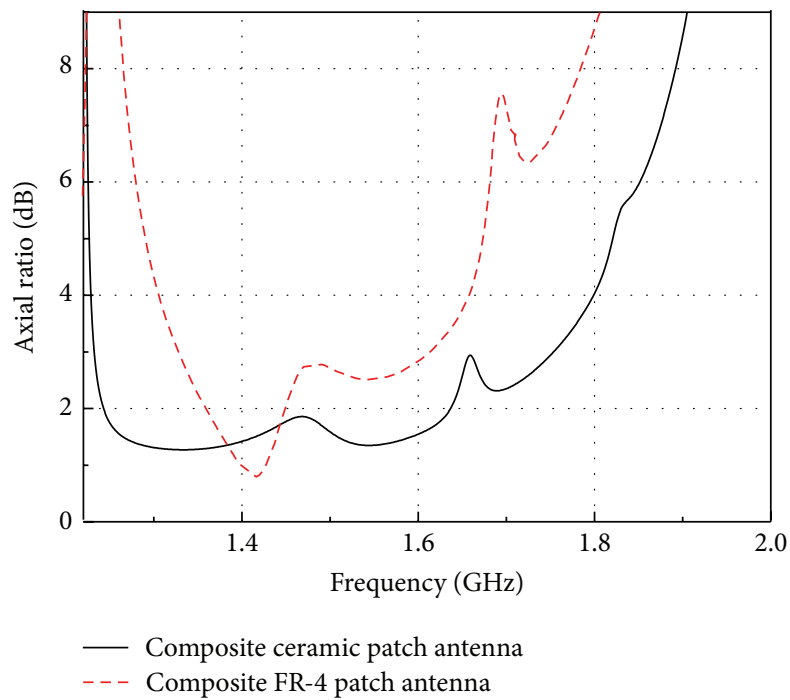

(b)

FIGURE 9: Comparison of the composite FR-4 patch antenna and composite ceramic patch antenna. (a) Measured impedance bandwidth, (b) AR bandwidth.

TABLE 1: The measured gain and AR of the composite FR-4 patch antenna and ceramic antenna.

\begin{tabular}{lccc}
\hline Freq. (GHz) & AR $(\mathrm{dB})$ & $\begin{array}{c}\text { RHCP } \\
\text { Gpeak }(\mathrm{dBi})\end{array}$ & $\begin{array}{c}\text { LHCP } \\
\text { Gpeak }(\mathrm{dBi})\end{array}$ \\
\hline \multicolumn{4}{c}{ Composite } \\
1.56 & 2.67 & 2.29 & \\
1.565 & 2.65 & 2.58 & -5.93 \\
1.57 & 2.61 & 2.63 & -5.51 \\
1.575 & 2.57 & 2.75 & -6.21 \\
1.58 & 2.56 & 2.21 & -6.29 \\
1.59 & 2.65 & 1.62 & -8.06 \\
1.60 & 2.76 & 1.52 & -9.07 \\
1.61 & 2.81 & 1.41 & -9.81 \\
1.62 & 2.84 & 1.36 & -12.33 \\
\hline & Composite ceramic patch antenna & -12.15 \\
1.56 & 1.42 & 2.28 & -6.01 \\
1.565 & 1.32 & 2.71 & -6.04 \\
1.57 & 1.35 & 2.67 & -6.21 \\
1.575 & 1.24 & 2.65 & -6.47 \\
1.58 & 1.51 & 2.20 & -8.88 \\
1.59 & 1.54 & 2.15 & -9.15 \\
1.60 & 1.52 & 1.66 & -9.70 \\
1.61 & 1.74 & 1.51 & -11.47 \\
1.62 & 1.98 & 1.47 & -8.15 \\
\hline
\end{tabular}

covering AR bandwidth of $1.205 \mathrm{GHz}$ to $1.785 \mathrm{GHz}$ as $3 \mathrm{~dB}$ $A R$ value. This paper is expected to promote the research and application of GPS antenna.

\section{Conflict of Interests}

The authors declare that there is no conflict of interests regarding the publication of this paper.

\section{Acknowledgment}

This research was supported by the Basic Science Research Program through the National Research Foundation of Korea (NRF) funded by the Ministry of Education (2015023260) and by the Soonchunhyang University Research Fund.

\section{References}

[1] L. Boccia, G. Amendola, and G. Di Massa, "Performance evaluation of shorted annular patch antennas for high-precision GPS systems," IET Microwaves, Antennas \& Propagation, vol. 1, no. 2, pp. 465-471, 2007.

[2] L. I. Basilio, J. T. Williams, D. R. Jackson, and M. A. Khayat, "A comparative study of a new GPS reduced-surface-wave antenna," IEEE Antennas and Wireless Propagation Letters, vol. 4, no. 1, pp. 233-236, 2005.

[3] S. Caizzone, N. Basta, and A. Dreher, "Compact GNSS antenna with circular polarization and low axial ratio," in Proceedings of the15th International Symposium on Antenna Technology and Applied Electromagnetics (ANTEM '12), pp. 1-3, IEEE, Toulouse, France, June 2012.

[4] F. Khosravi, H. Moghadas, and P. Mousavi, "A GNSS antenna with a polarization selective surface for the mitigation of lowangle multipath interference," IEEE Transactions on Antennas and Propagation, vol. 63, no. 12, pp. 5287-5295, 2015.

[5] J. J. H. Wang, "Antennas for global navigation satellite system (GNSS)," Proceedings of the IEEE, vol. 100, no. 7, pp. 2349-2355, 2012. 
[6] K. Y. Lam, K.-M. Luk, K. F. Lee, H. Wong, and K. B. Ng, "Small circularly polarized U-slot wideband patch antenna," IEEE Antennas and Wireless Propagation Letters, vol. 10, pp. 8790, 2011.

[7] L. Boccia, G. Amendola, and G. Di Massa, "A dual frequency microstrip patch antenna for high-precision GPS applications," IEEE Antennas and Wireless Propagation Letters, vol. 3, no. 1, pp. 157-160, 2004.

[8] S. Chen, G. Liu, X. Chen, T. Lin, X. Liu, and Z. Duan, "Compact dual-band GPS microstrip antenna using multilayer LTCC substrate," IEEE Antennas and Wireless Propagation Letters, vol. 9, pp. 421-423, 2010.

[9] X. L. Bao and M. J. Ammann, "Dual-frequency circularlypolarized patch antenna with compact size and small frequency ratio," IEEE Transactions on Antennas and Propagation, vol. 55, no. 7, pp. 2104-2107, 2007.

[10] G. Liu, L. Xu, and Y. Wang, "Modified dual-band stacked circularly polarized microstrip antenna," International Journal of Antennas and Propagation, vol. 2013, Article ID 382958, 5 pages, 2013.

[11] X. Ye, M. He, P. Zhou, and H. Sun, "A compact single-feed circularly polarized microstrip antenna with symmetric and wide-beamwidth radiation pattern," International Journal of Antennas and Propagation, vol. 2013, Article ID 106516, 7 pages, 2013.

[12] S. X. Ta, J. J. Han, I. Park, and R. W. Ziolkowski, "Widebeam circularly polarized crossed scythe-shaped dipoles for global navigation satellite systems," Journal of Electromagnetic Engineering and Science, vol. 13, no. 4, pp. 224-232, 2013.

[13] P. Jin, C.-C. Lin, and R. W. Ziolkowski, "Multifunctional, electrically small, planar near-field resonant parasitic antennas," IEEE Antennas and Wireless Propagation Letters, vol. 11, pp. 200204, 2012.

[14] P. Jin and R. W. Ziolkowski, "Multi-frequency, linear and circular polarized, metamaterial-inspired, near-field resonant parasitic antennas," IEEE Transactions on Antennas and Propagation, vol. 59, no. 5, pp. 1446-1459, 2011.

[15] J.-A. Hou and Y.-H. Wang, "A compact quadrature hybrid based on high-pass and low-pass lumped elements," IEEE Microwave and Wireless Components Letters, vol. 17, no. 8, pp. 595-597, 2007.

[16] Y.-C. Chiang and C.-Y. Chen, "Design of a wide band lumped element $3 \mathrm{~dB}$ quadrature coupler," IEEE Transactions on Microwave Theory and Techniques, vol. 49, no. 3, pp. 476-479, 2001. 


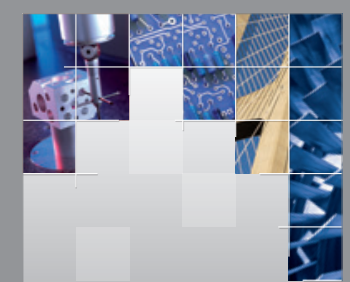

\section{Enfincering}
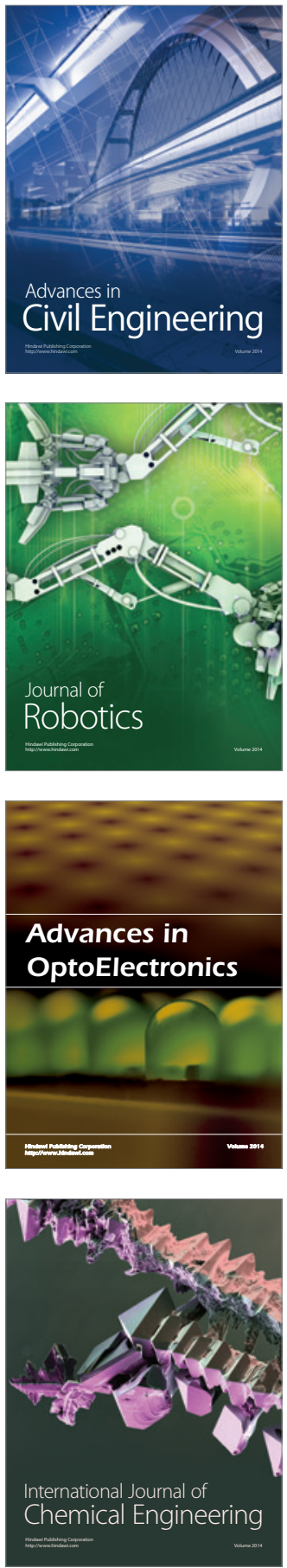

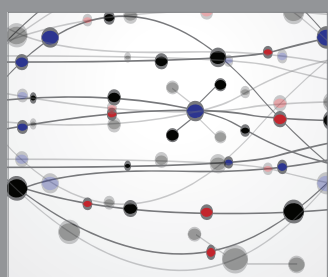

The Scientific World Journal

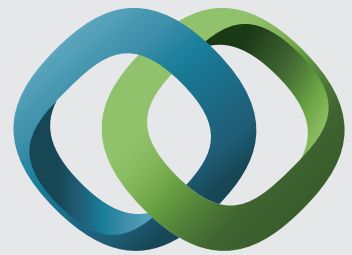

\section{Hindawi}

Submit your manuscripts at

http://www.hindawi.com
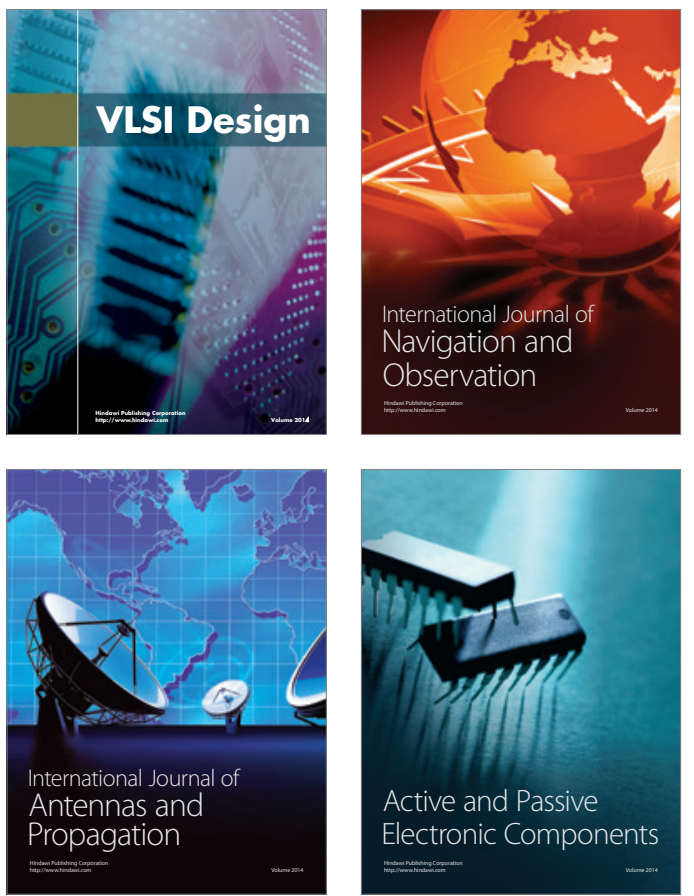
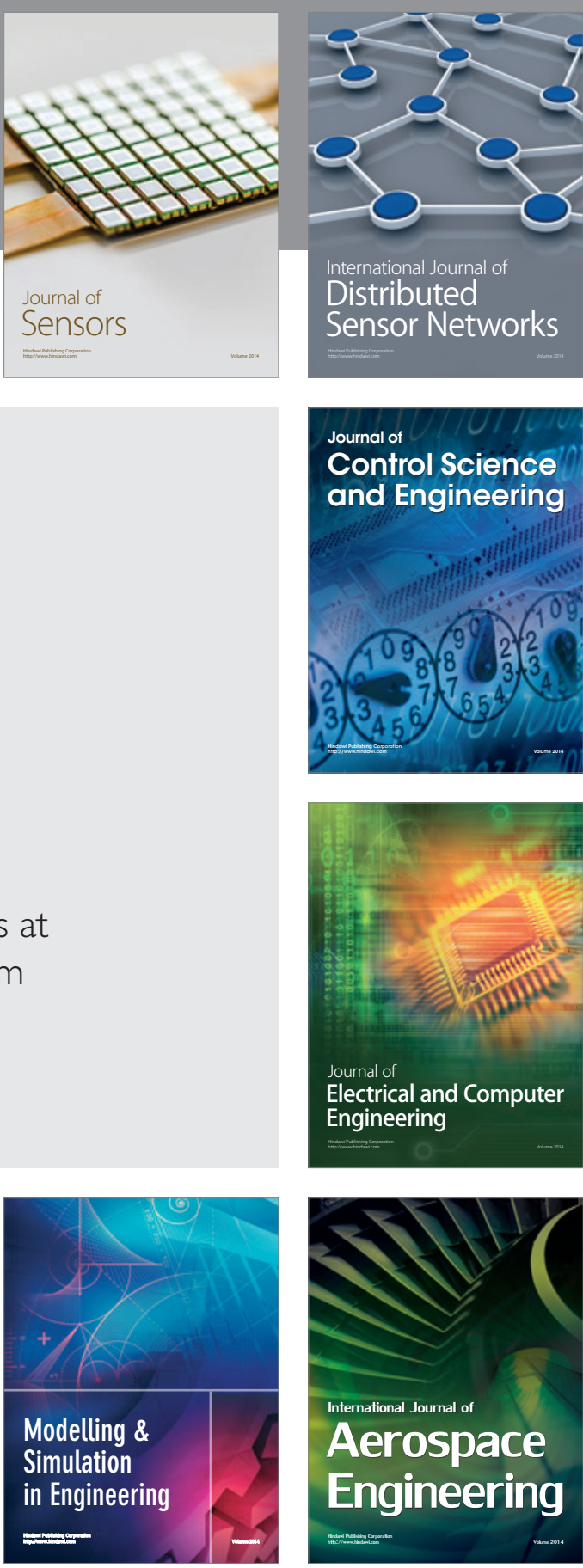

International Journal of

Distributed

Sensor Networks

Journal of

Control Science

and Engineering
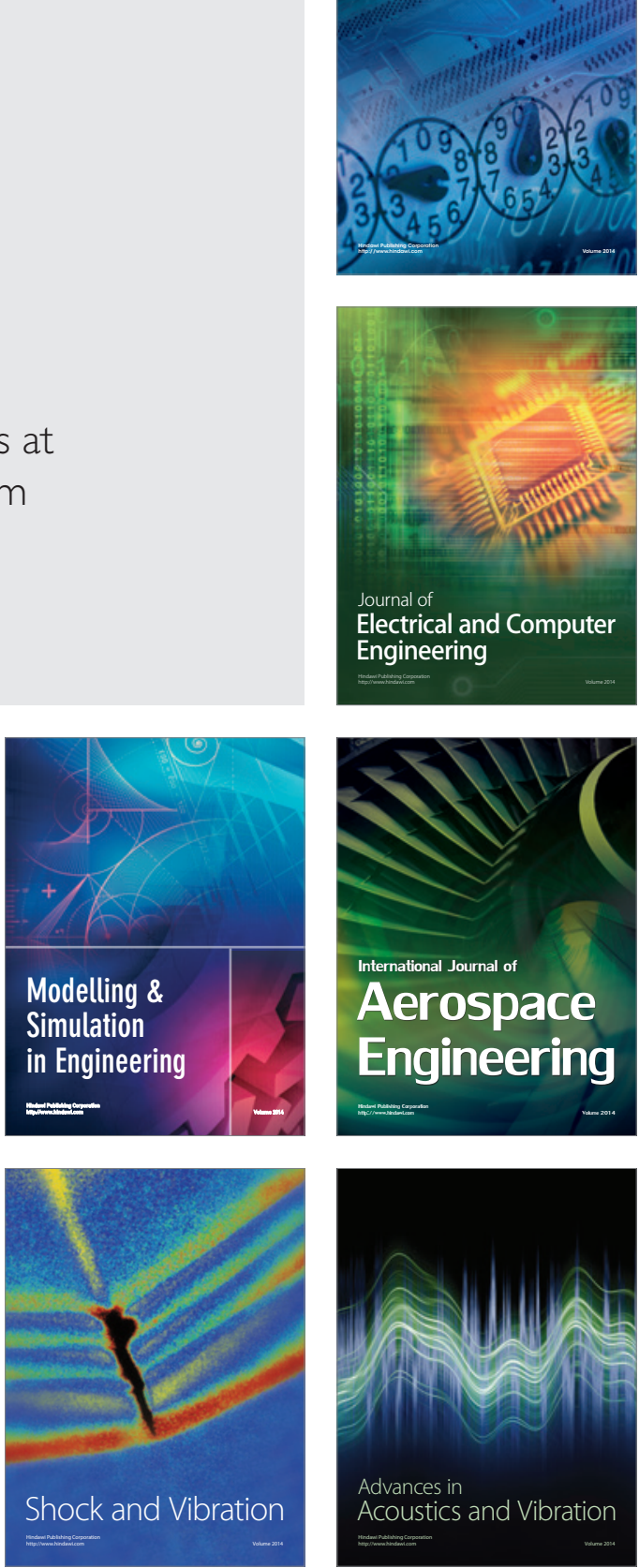